\title{
Pricing Mechanism of Charging Pile Power Supply Market Based on RTP Theory and Price Discrimination Model
}

\author{
Shiyao Ding ${ }^{1, *}$, Siqi Zhang ${ }^{2}$ \\ ${ }^{1}$ School of economics, Nanjing University of Posts and Telecommunications \\ 2 School of management, Nanjing University of Posts and Telecommunications
}

\begin{abstract}
Based on the data of monopoly enterprises in China's new energy charging pile power retail market, this paper explores the application of RTP differential pricing in new areas. First of all, from the perspective of business, this paper constructs the incentive cost model of low period which can minimize the supply pressure of power sales enterprises. Then, from the perspective of charging consumers, based on the assumption of user's conversion cost, an improved demand response model is established according to the price elasticity. The paper is to consider the premise of maximizing social welfare, in the supply and demand of both sides to improve the pressure of electricity measurement, to minimize the operation and maintenance costs in peak and trough period.
\end{abstract}

\section{Introduction}

As a country with a relatively large carbon emission in the world, China's government is actively introducing more environmentally friendly production and use process to the traditional power generation mode to accelerate the development and utilization of renewable resources. However, with the growth of population and the upgrading of productivity, the power demand of the society is still increasing day by day. In the traditional sense, the improvement of power supply efficiency is mainly for the maintenance and upgrading of hardware, such as expanding the installed capacity or transferring power from outside, which will undoubtedly increase certain additional costs, and it is not conducive to reducing the peak load pressure but will meanwhile have an invisible impact on the environment.

When it comes to the alleviation of the imbalance between supply and demand, which lead to high cost in peak period, RTP is a widely accepted pricing strategy. But when it is applied to the profit-making enterprises, it is divided into two views. Some scholars believe that this strategy can improve social welfare, while others do not.

Based on this controversy, this paper identifies users with different preferences through price elasticity of demand, and then establishes two kinds of subsidy models. The first kind studies the situation of minimum supply pressure for enterprises, that is, to find incentive costs when the peak and trough reach the optimal smooth state. The second kind studies the possibility of transforming Fixed Uniform Pricing (FUP) into RTP, and provides incentives to consumers in peak hours, Turn it into the receiver of RTP.

This paper cites the central point of Sales [1], that is, there is an improved demand response (DR, here after) program, in which only a small number of consumers with active cost saving switch to RTP, as the basic assumption. There are three innovations in this paper: first, the model in Sales considers cost to be consistent. Since Power supply cost may vary in peak and low periods in reality, so we build two different cost functions based on our data to show more meaningful results. Secondly, this paper based on the data supplied by the monopolies in the power retail market of China's new energy charging piles to supplement and demonstrate the hypothetical, which proves that the differential pricing model can be applied to the power retail field of charging piles. Thirdly, this paper explores the cost that users need to pay to achieve consumption strategy transformation from the perspective of power retailers, so as to maximize the pressure of power side and minimize the operation and maintenance cost during peak and trough periods.

\section{Literature Review}

\subsection{Real-Time-Pricing}

It is widely accepted that the transmission mechanism of demand side response is a supply and demand chain. When the power company detects that the electricity consumption is in peak hours, the users will receive the price adjustment instructions from the company. According to the dynamic change of electricity price and electricity policy, the inherent mode of electricity consumption will be changed temporarily. Through this mode, the power load of a certain period can be reduced or shifted to respond to the power supply, so as to ensure the stability of the power grid system.

*Corresponding author: 1015266371@qq.com 
Demand side real-time price is one of the important means of price-based demand response in power market. Compared with TOU, which cannot cope with short-term capacity shortage, RTP mode design is more reasonable.

Real time pricing allows enterprises to set flexible prices for goods or services based on real-time demand. Prices will be adjusted according to changes in supply and demand, competitors' prices and other market conditions. Although RTP theory can be traced back to price discrimination theory and dynamic pricing strategy, the application of real-time pricing strategy in retail industry, especially in power industry, still needs to be developed. According to the voluntary RTP participation rate of the U.S. power industry surveyed by Barbose, only about $1 \%$ of the total installed power generation capacity of the U.S. may be controlled by RTP mode, and one third of the projects even have no participants [2]. Behind this, the main reason for the application obstacle is that it is necessary for users to perceive the change of electricity price and reduce the frequency of peak electricity consumption, but it involves a large learning cost. In the past, RTP projects were mainly carried out in European and American countries, most of which involved industrial users. Industrial users can quickly respond to price or incentive signals and reduce a lot of electricity demand, so it is very suitable for demand response projects. At present, the interaction between individual users and power grid is relatively small.

However, most of China's service grid industry is in the 'B2C' mode. Users charge their cars through mobile phone clients. On the one hand, real-time data is accurately recorded by charging service enterprises. On the other hand, users can also perceive the change of electricity price through the platform information released in real time. Therefore, merchants can predict the low peak period of electricity price through RTP model. Influence user behavior, such as issuing coupons in low peak hours, publishing real-time messages and other ways to drain peak demand. As a result, the response characteristics of its customers will be closer to David's definition of users with 'commensurate price attractiveness' [3].

\subsection{Relations between Three-level Price Discrimination and E-coupon}

According to Western Economic Theory, three-level price discrimination refers to monopoly manufacturers charging different prices for the same product in different markets or different consumer groups [4]. In the era of big data, technology makes the information between enterprises and consumers more transparent. On the one hand, price discrimination in the traditional sense, that is, charging different prices to different consumer groups becomes easier because the types of consumers are easier to reveal [5]. On the other hand, it may be more difficult, because the motivation of enterprises may have obvious differences in different clients.

As a new and efficient means of network marketing, e-Voucher is helpful to reduce costs, guide customers to change consumption habits and increase consumption times. The academic research in this field is mainly focused on two aspects: the description of the delivery object and the analysis of the delivery effect.

Among them, some scholars build models based on stock market. Xinxin uses activity to distinguish different users and proposes a two-stage hybrid model [6]. Dass designs differentiated coupon discount values by solving an optimization problem [7]. Other scholars study the utility of e-coupons based on incremental market. Kui studies the impact of e-coupons on corporate profits through the data set of e-coupons transaction in Texas liquor sales data, and the total social welfare has increased [8].

\subsection{Price discrimination in Electricity industry}

In the literature of power retail industry, scholars usually have two main research directions. In the first direction, use the government targeted tax and transfer payment methods to strengthen market equity. In the study of Australian electricity market, scholars propose to introduce cap price cap regulation into effective competition market in order to minimize the damage to market operation. Meanwhile, to prevent the companies that charge excessive profits from "sticky customers" to pay too much for power services due to long-term marginal costs [9], the long-term preferential interest rate of all families is reduced by $1-2 \%$, and $10-30 \%$ discount is provided to vulnerable families [10]

The second direction is to establish price model to complete differential pricing. The logic behind the research direction is that the high-cost users enjoy low price will lead to excessive consumption and waste economic resources. The high price of low-cost users will lead to the reduction of production scale, and social losses due to insufficient production. This brings in two new questions: applying the theory of three-level price discrimination to the field of power retail. How can a single enterprise identify users with different demands? How can these users subsidize each other?

In view of a series of problems, Ze assumes that there are only two types of users, residents and industrial users in grid enterprises. Residents are subsidized parties with cross subsidies, and industrial users provide cross subsidy parties. The model of enterprise pricing is set up based on the optimization of social welfare as the objective function [11]. Stephen's research found that the ratio of fixed cost and variable cost has a systematic difference trend in different segments according to the user consumption. Thus, mutual subsidies for different segments are done through FM ratio model [12]. Klaus, from the perspective of asymmetric competition between new entrants and in-service suppliers, finds that the retailer pricing strategy may consider the information level of consumers through empirical research on German retail power market. When the search volume of consumers increases, the local existing enterprises will increase the marginal profit, obtain the surplus from loyal consumers, and the entrants will reduce the price. In essence, the whole market subsidizes each other 
among consumers according to the search effort under the free competition.

The innovation of this paper is mainly reflected in the following aspects: first, based on the proof of Corsi's mechanism of price elasticity on RTP theory, the elasticity of price in each period of the day is regarded as the boundary between peak and low [13]. Secondly, in the model design, sales only considering the situation that social welfare is unchange and the enterprise does not lose money [1]. This paper supplements the reasons for the implementation of RTP by the enterprise entities and the return obtained -- smooth the supply and demand of peak and low valley, thus reducing the Zero selling cost of power service in peak period. Third, based on the empirical analysis and model test of industrial real data, samimi's article establishes the utility function of consumers based on five reasonable assumptions about consumer consumption [14]. This paper takes the real data of the power retail enterprises and analyzes the specific consumers under the data settled.

\section{Data and Benchmark Model}

\subsection{Data source}

Through cooperation with retail head enterprises of new energy charging piles in China, we selected 31 provinces, cities and regions in mainland China to obtain 10139 real-time data of charging piles for analysis. The market share of this enterprise is $24.9 \%$, which is in a monopoly position in the charging pile market. The company is one of the leading electric vehicle charging operators in China. At present, there are more than 410000 self-built charging equipment terminals on the platform, covering 350 cities, with a daily charging capacity of more than 8 million kwh. The real-time data of charging pile includes charging time, charging quantity, charging real-time price, charging cost and other variables. Via Stata 15.0 software cleans and shrinks the data, and finally gets 9918 valid data. Among them, 4122 distributed in the peak period and 5796 in the trough period.

\subsection{Model hypothesis}

Firstly, according to the practice of the electricity market and the actual electricity consumption reflected in the data, 20:00-8:00 the next day (12 hours) is defined as the trough period, and 8:00-20:00 (12 hours) is defined as the peak period. At the same time, the optimal power supply of enterprises is also different in the peak and trough periods.

Secondly, due to the high market share of the enterprise in the selected area and the wide distribution of charging piles, this paper ignores the impact of charging pile distribution and charging convenience on consumer decision-making.

Thirdly, due to the lack of consumer's digital variables data, we assume that consumer behavior is consistent and share the same price elasticity and demand function.
Fourthly, by default, it costs to make users change from FUL to RTP, but the cost may be positive or negative. In the case of positive cost, users think that switching power consumption time makes their consumption habits more inconvenient. When the cost is negative, some users will take the initiative to choose RTP mode for the sake of economic saving or environmental protection. This paper assumes that some users prefer FUP, that is, they stick to the power consumption mode in time and are not easy to change their habits, while another type of users prefer RTP, that is, they are easy to change their consumption time due to the fluctuation of real-time electricity price, or there are user groups that attach importance to environmental protection and social welfare. In the previous literature, most scholars define the cost as a positive number greater than or equal to 0 . For example, Kui thinks that the switching cost of active users is in the range of $[0, \theta]$. In the interval, it is positive everywhere and log concave function, that is, the function type of uneven distribution [15].

In order to simplify the period, it is reasonable to think that the switching cost is evenly distributed. Since there are users who are willing to actively switch, we extend the switching cost range to $[-\theta, \theta]$, let $t \in[-\theta, \theta]$, which is the critical point of the transformation. Users will choose not to change the power consumption period when switching cost is in the range of $[-\theta, t]$, otherwise will change.

\subsection{Demand function and supply function}

We further calculate the demand function for peak and trough periods as sum inverse demand function and cost function. Stata 15.0 software was used for data cleaning, tailing and region regression. All region results could be found in the appendix.

The subscript 1 denotes the result for low period and the subscript $h$ denotes the result for high period.

\subsubsection{For consumers}

Based on the consumer's consumption decisions under different electricity prices, we calculate the consumer's demand function in the low and peak periods below:

$$
q_{l}(p)=-8.32 p_{l}+34.78
$$

So the inversed demand function is:

$$
p_{l}(q)=-0.12 q_{l}+4.18
$$

Similar, use high period data, and the demand function of consumers is:

$$
q_{h}(p)=-3.62 p_{h}+25.34
$$

So the inversed demand function is:

$$
p_{h}(q)=-0.28 q_{h}+7
$$

\subsubsection{For firm}

We calculate the cost function of the enterprise according to the total cost of power supply and the 
power supply quantity. At the same time, we calculate the optimal supply function of the enterprise in the peak and low periods under the principle of maximizing profits.

The total cost function in low period is

$$
t c\left(q_{l}\right)=0.0004 q_{l}^{2}+0.368 q_{l}+0.604
$$

Use first derivative to figure out marginal cost function:

$$
m c\left(q_{l}\right)=0.0008 q_{l}+0.368
$$

We assume profit $=\mathrm{p} * \mathrm{q}-\mathrm{tc}(\mathrm{q})$ and got:

$$
s\left(p_{l}\right)=1250 p-460
$$

Similar, high period supply function is:

$$
s\left(p_{h}\right)=714 p-661
$$

\begin{tabular}{|c|c|c|c|c|}
\hline \multirow[b]{2}{*}{ Variables } & \multicolumn{2}{|c|}{ Demand } & \multicolumn{2}{|c|}{ Supply } \\
\hline & Demand $_{h}$ & Demand $_{l}$ & Supply $_{h}$ & Supply $_{l}$ \\
\hline $\mathrm{Ph}$ & $\begin{array}{c}-3.622 * * * \\
(-3.07)\end{array}$ & & $0.926 * * *$ & \\
\hline $\mathrm{pl}$ & & $\begin{array}{c}-8.321 * * * \\
(-6.45)\end{array}$ & & $\begin{array}{c}0.368 * * * \\
(36.30)\end{array}$ \\
\hline Constant & 25.342 & 34.783 & 1.048 & 0.604 \\
\hline R-squared & 0.005 & 0.014 & 0.810 & 0.538 \\
\hline Observations & 4122 & 5796 & 4122 & 5796 \\
\hline
\end{tabular}

The specific regression table and correlation coefficient are as follows.

Table 1 Cusumer demand and firm supply

\section{The smoothest sales strategy}

\subsection{Fixed uniform pricing (FUP)}

We assume that the profit of the enterprise is 0 at this time and use FUP pricing to balance the peak and trough costsa.

In FUP mode, through the demand function of high and low period as well as the distribution proportion

formula of peak and trough

$$
P=\frac{12 q_{h}{ }^{a} m c\left(q_{h}\right)}{Q}+\frac{12 q_{l}{ }^{\circ} m c\left(q_{l}\right)}{Q},
$$
we can get the demand, cost and price before the transformation.

Because at the same price, it must be satisfied the relation of $P_{l}=P_{h}=P_{F U L}$. The results are as follows, $P=0.64, q_{l}=23, q_{h}=29, Q=630$. It can be seen that under the unified price, the demand in peak hours is higher than that in trough hours.

\subsection{Real time pricing (RTP)}

Under the strategy of time-sharing pricing, enterprises can set different prices for high and low. RTP pricing strategy has a strong practical significance to reduce the supply of power and other public resources. This paper effectively suppresses price fluctuations by balancing

${ }^{\text {a }}$ Salies E . Real-time pricing when some consumers resist in saving electricity[J]. Energy Policy, 2013, 59(aug.):843-849. supply and demand. By reducing the supply of public resources in high period, the pressure of infrastructure operation can be smoothed.

We still assume that the profit of the enterprise is zero. At this time, the supply of electricity retail market is equal to the demand. Through the simultaneous equation $s\left(p_{l}\right)=q_{l}^{r}$ and $s\left(p_{h}\right)=q_{h}^{r}$, thought which we can figure out $p_{h}^{r}=0.96, p_{l}^{r}=0.39, q_{h}^{r}=32, q_{l}^{r}=22$. The calculation method of RTP makes the price difference between high peak and low significant.

\subsection{Incentive cost of the Smoothest Strategy}

When the enterprises construct and maintain the corresponding infrastructure, they need to consider meeting the highest demand. Therefore, the excessive difference of power consumption in high and low period will cause great waste and improve the operation and maintenance cost of the enterprise. In order to reduce the cost of the enterprise, we first how to smooth the high and low sales margin by issuing discount coupons in a specific period of time on the platform.

There is a large demand for electricity in high period, so retailers should issue e-coupons that can only be consumed in low period to guide demand. We assume that for users who consume in low peak period, the enterprise will provide one-time subsidy $\mathrm{m}$. It is assumed that the subsidy will not affect consumers' consumption behavior during peak hours. Without subsidy, the consumer utility function is $U_{x}\left(q_{x}\right)=\int_{0}^{q_{x}} p_{x}(q) d q(x=h, l)$. With a subsidy $\mathrm{m}$ added, the new utility function is $U_{l_{2}}=\left(q_{l}, m\right)=U_{l}\left(q_{l}\right)+m$

Suppose that the change of demand due to subsidies during the low peak period is $\mathrm{n}$, and under the condition of supply and demand balance, the demand for subsidies is $\mathrm{n}, q_{h}=s\left(p_{h}\right)=$ demand $_{h} q_{l}=s\left(p_{l}\right)=$ demand $_{l}+n$. If $\mathrm{qh}=\mathrm{ql}$, we could have $p_{l}=0.388-0.0008 n$

Use the utility function before adjustment $U_{\text {before }}=\int_{0}^{(n+0.388)}\left[-3.62 p_{l}+25.34+n\right]$ And the after $U_{\text {affer }}=\int_{0}^{(n+0.388)}\left[-3.62 p_{l}+25.34\right]$ to get the difference, we know that $\Delta U=(n+0.194)^{2}-0.038$. When $\Delta U \geq 0$, or to say $n \geq 9.3 \times 10^{-4}$, It can be deduced from the expression that the subsidy's starting point is low and the growth effect is remarkable, which is a good choice for enterprises. 


\section{The price strategy of social welfare maximization}

\subsection{Research on the cut-off point of conversion from FUP to RTP}

In this model, we consider the cost and benefit of full adoption of RTP. Based on Hypothesis 4 of our model, in the process of charging price changing from unified pricing to real-time pricing, different users have different adaptation cost $\mathrm{C}$, and $\mathrm{C}$ is in line with uniform distribution.

We assume that the threshold of the transformation is $\mathrm{t}$, which means when $\mathrm{c}<\mathrm{t}$, users would choose RTP and when $c \geq t$, users would choose stick to FUP, and firms would lose this part of users when they apply RTP to the whole market. We assume the cost would affect the utility for high period. So the new utility function for high period is $\frac{\partial u_{h}\left(q_{h}^{r}, t\right)}{\partial q_{h}}=U_{h}^{\prime}\left(q_{h}^{r}\right)+t$.

So the new utility function of high period is $U_{h}\left(q_{h}^{r}\right)=-1.81 p_{h}^{2}+17.67 p_{h}$ and the low period is $U_{l}\left(q_{l}^{r}\right)=-4.16 p_{l}^{2}+34.78 p_{l}$. We make the consumer surplus of FUP equal to that of adjusted RTP as follow:

$12\left(U_{n}\left(q_{n}^{r}, t\right)-p_{n}\left(q_{n}^{r}, t\right) q_{n}^{r}\right)+12\left(U_{l}\left(q_{l}^{r}, t\right)-p_{l}\left(q_{l}^{r}, t\right) q_{l}^{r}\right)=12\left(U_{n}\left(q_{n}\right)-p q_{n}\right)+12\left(U_{I}\left(q_{l}\right)-p q_{l}\right)$

The simplified formula is $t=\frac{\Delta C S_{h}+\Delta C S_{l}}{q_{h}}$

In fact, the remaining sum of the consumers in the two periods is divided equally into the converted sales volume in each peak period, which is the conversion cost per unit user. We come to the conclusion that:

$\Delta C S_{h}=-10.39-\left(-1.81 p_{h}^{r 2}+12.78 p_{h}^{r}\right)+p_{h}^{r}\left(-4.16 p_{h}^{2}+17.39 p_{h}\right)(10)$

$\Delta C S_{l}=30.40$. After further simplification, the decomposition points of transformed users and conservative users is $t=-4.16 p_{h}^{3}+19.2 p_{h}^{2}-12.78 p_{h}-10.39$.

As shown in the figure 2 below, it can be seen that the higher the pricing in high period, the greater the driving force for users to convert to RTP type, which can be shown as the reduction of conversion cost $t$, and the relationship between the two is inverse in the price range studied.

\subsection{Incentive cost of Pareto improvement}

Based on the above assumption of $\mathrm{t}$ and $\theta$.We set the user interval $(t, \theta)$ which refuses to convert to RTP as $\alpha$, then accept the converted user in $(-\theta, t)$ is $1-\alpha$. We give one-time subsity $\mathrm{m}$ to users who are willing to convert to RTP to encourage more people to convert to RTP. By adding the increased cost of customer $1-\alpha$ to the left side of formula (5). We get the following formula:

$$
t=-4.16 p_{h}^{3}+19.2 p_{h}^{2}-12.78 p_{h}-10.39+2 m
$$

As can be seen from Figure 1, when the peak price is higher than the FUP price in a certain range, the two variables are proportional to each other, which is in line with the expectation.

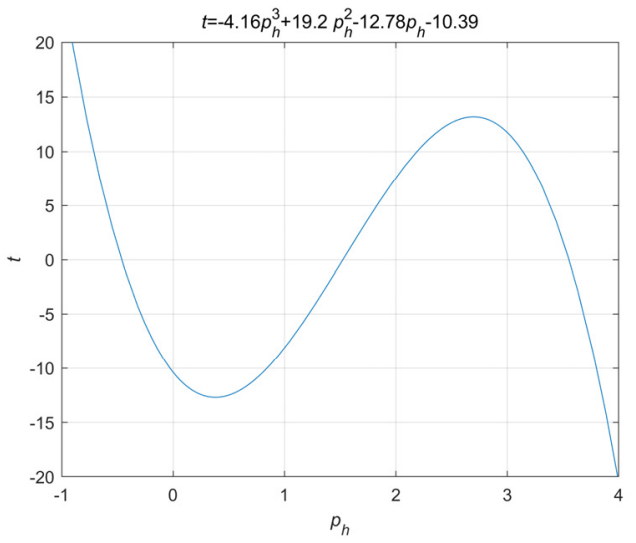

Fig. 1. Relation between $\mathrm{m}$ and high period

In order not to lose the retailer's profit before and after using the strategy and to make the profit under FUP equal to the profit after subsidy under RTP, the formula must satisfy the following conditions:

$$
\alpha \pi^{f}+(1-\alpha)\left(\pi^{r}\left(p_{h}\right)-m\right)=\pi^{f}
$$

Where $\alpha=\frac{\theta-t}{2 \theta} \quad \pi^{f}=\left(p_{h}\left(q_{h}^{r}\right)-m c\left(q_{h}^{r}\right)\right) q_{h}^{r}$. Because $\theta$ is defined arbitrarily, In order to make the conclusion comparable, In this paper, the value of $\theta$ is 100 according to Salie (2013). When (11) and (12) are combined, the relationship between $\mathrm{M}$ and $p_{h}$ is obtained as follow:

$$
-4.16 p_{h}^{3}+19.2 p_{h}^{2}-12.78 p_{h}-10.39=\frac{-2 m^{2}+100 m-18.6}{m-0.246}
$$

Under the cost incentive $m=31.51$, the number of users willing to convert to RTP increased by $14.7 \%$ $(t=-71.66)$. Compared with the case without incentive cost, the effect is significant.

\section{Discussion and Conclusion}

Since the concept of real-time pricing was put forward by Caramanis [16], its connotation and scope have been expanding. In the beginning, the price of electricity on the supply side was self-adjusted only according to the power generation situation. Later, the smart grid came into being, gradually realizing the supply side adjustment model according to the consumption fluctuation on the demand side, realizing the rebalancing of supply and demand. In order to further feedback the feasibility of using RTP method in the power retail industry, guide the power retail industry to help the power grid realize "peak shaving and valley filling". This paper mainly makes the following explorations:

First, from the perspective of enterprise benefit, in order to reduce the waste caused by the large difference between peak and low peak power consumption, two scenarios of the smoothest supply and demand and the 
maximum user conversion rate are proposed, which provide theoretical guidance for power retail enterprises.

Secondly, under the appropriate industry and supportive government policy, the feasible RTP price strategy is studied. Although RTP is discussed more and more widely in the academic field, its application in the industry is always low. The root reason is that the social welfare of both supply and demand has not been significantly increased and the attraction is poor. The research of this paper is based on the client, and the conversion rate can be improved quickly by issuing Econsumer bonds.

Thirdly, it is representative to use the actual data to simulate the balance between supply and demand. At present, smart grid has not been popularized, and the results of simulation algorithm need to be verified in reality. Finally, several pricing strategies in this paper can significantly improve the efficiency of enterprise distribution and customer group, which has practical significance.

\section{References}

1. Salies E . Real-time pricing when some consumers resist in saving electricity[J]. Energy Policy, 2013, 59(aug.):843-849.

2. Barbose G, Goldman C, Neenan B . A Survey of Utility Experience with Real Time Pricing. Lawrence Berkeley National Laboratory, 2004.

3. David A K, Li Y Z. Consumer rationality assumptions in the real-time pricing of electricity[J]. IEE Proceedings $\mathrm{C}$ - Generation, Transmission and Distribution, 1992, 139(4):315-322.

4. Gao Hongye. Western economics [M]. Beijing: China Renmin University Press, 2005: 223

5. Shiller B . First Degree Price Discrimination Using Big Data[J]. Social Science Electronic Publishing, 2013, 64(518):419-438.

6. Ren Xinxin,Cao Jingjing,Xu Xianhao,Gong Yeming (Yale). A two-stage model for forecasting consumers' intention to purchase with e-coupons[J]. Journal of Retailing and Consumer Services, 2020 (prepublish).

7. Dass, Rajanish. Dynamic pricing using e-coupons[J]. International Journal of Internet Marketing \& Advertising, 2005, 2(1/2):78-91.

8. Lu Kui, Hu Hanhui, Wu Chong. Price competition in retail electricity market: Based on multi type users and differentiated switching costs [J]. Systems engineering theory and practice, 2012,32 (12): 26442655

9. Simshauser, Paul. When Does Electricity Price Cap Regulation Become Distortionary?[J]. Australian Economic Review, 2014, 47.

10. Simshauser P, Whish-Wilson P. Price discrimination in Australia's retail electricity markets: An analysis of Victoria \& Southeast Queensland[J]. Energy Economics, 2016, 62(FEB.): 92-103.
11. Ye Ze, Yao Jun, Wu Yongfei, et al. Research on cross subsidy and social welfare measurement considering user demand [j]. China electric power, 2019, 052 (012): 113-122

12. Stephen Davies and Catherine Waddams Price and Chris M. Wilson. Nonlinear Pricing and Tariff Differentiation: Evidence from the British Electricity Market[J]. The Energy Journal, 2014, 35(1)

13. Pc A, Pf B, Zv B . Effects of elasticity parameter definition for real-time pricing remuneration considering different user types[J]. Energy Reports, 2020, 6:127-132.

14. Samimi A, Nikzad M, Mohammadi M . Real-time electricity pricing of a comprehensive demand response model in smart grids: Real-time demand response model[J]. International Transactions on Electrical Energy Systems, 2016, 27(3):1-15.

15. Xie C, Consulting N . Price Discrimination and Consumer Retention: The Case of e-Coupons.

16. Caramanis M . Optimal Spot Pricing : Practice and Theory[J]. IEEE Trans Power Apparatus Syst, 1982, 101(9):42-42. 